\title{
Comparing the Efficacy of Oral Chloroquine versus Oral Tetracycline in the Treatment of Cutaneous Leishmaniasis
}

\author{
Fahmida Malik1, Malik Muhammad Hanif1 and Ghulam Mustafa2
}

\begin{abstract}
Objective: To compare the efficacy of oral chloroquine versus oral tetracycline in the treatment of cutaneous leishmaniasis (CL).

Study Design: Interventional comparative study.

Place and Duration of Study: Department of Dermatology, Sheikh Zayed Hospital, Rahim Yar Khan, from July 2017 to January 2018.

Methodology: Cases of CL with age 12 years or above were included. The diagnosis of cutaneous leishmaniasis was made on the basis of history of travel to rural endemic area and clinical features of non-healing ulcer and on detection of Amastigotes on Giemsa staining on smear taken from the involved site. A total of 50 patients were selected randomly. They were divided into two groups. Group A was treated with chloroquine in a dose of $250 \mathrm{mg}$ twice daily per oral $(10 \mathrm{mg} / \mathrm{kg} / \mathrm{day})$ and Group B was treated with doxycycline in a dose of $200 \mathrm{mg}$ daily per oral (3.3 mg/kg/day). They were followed up for three months. Efficacy was labelled as 'yes' where there was complete re-epithelisation or healing with or without scarring of the lesions with no induration.

Results: There were a total of 50 cases, 25 were in each group. The mean age in group A and B was $30.56 \pm 7.14$ and $27.96 \pm 6.97$, respectively with $p=0.199$. All the cases belonged to rural population and were from endemic areas. There was no difference in terms of site of lesion. Upper limbs were the most common in both groups with $p=0.34$. The efficacy in group A was $100 \%$ while in group B it was $23(92 \%)$ of cases with $p=0.14$.

Conclusion: Oral tetracycline is as efficacious as oral chloroquin in the treatment of cutaneous leishmaniasis.
\end{abstract}

Key Words: Cutaneous leishmaniasis, Chloroquine, Tetracycline.

\section{INTRODUCTION}

Cutaneous leishmaniasis is one of the major concerns in the developed as well as developing countries like Pakistan due to majority of its population as rural residents. ${ }^{1-3}$ Leishmania (L.) has wide range of species that can affect human in various ways and is spread by the bite of a sand-fly. 4

World Health Organization (WHO) had divided it into two major subtypes, i.e. Old World and New World type. Old world is usually caused by L. major, L. aethiopica, L. infantum and L. tropica, and is found more in Indian subcontinent, Mediterranean area and Western Asia; while the New World type is affected by L. amazonensis, L. braziliensis and L. peruviana, and is prevalent in United States and Brazil. 5

There are classical indurated, ulcerated and with or without super added infected lesions and can involve any part of the body; but usually, on exposed sites.

Department of Dermatologyl / Community Medicine ${ }^{2}$,

Sheikh Zayed Medical College and Hospital, Rahim Yar Khan, Pakistan

Correspondence: Dr. Fahmida Malik, Department of

Dermatology, Sheikh Zayed Medical College and Hospital,

Rahim Yar Khan, Pakistan

E-mail:fahmidamalik77@gmail.com

Received: July 13, 2018; Accepted: November 14, 2018
Spontaneous healing is quite common but it takes usually 6 months to 1 year and may end up in a disfiguring scar and other complications. ${ }^{6-8}$

Treatment options of the disease include both systemic and topical therapies. Availability, cost, efficacy and side effects profiles of the drugs are the major parameters for selection of the drugs. Chloroquine is found to be active against intracellular amastigotes in macrophage infected cultures.9,10 Tetracyclines were also used recently. The mechanism by which they act is complex and is usually due to their anti-inflammatory capabilities. ${ }^{11}$ These agents are also easily available and cost-effective and have shown good efficacy. Chloroquine has well known side effects, more commonly retinopathy and GIT upsets compared to the tetracycline, which has fewer side effects. The present study compares these two drugs to find the better one.

The objective of this study was to compare the efficacy of oral chloroquine versus oral tetracycline in the treatment of cutaneous Leishmaniasis.

\section{METHODOLOGY}

It was an interventional comparative study, conducted at the Department of Dermatology, Sheikh Zayed Hospital, Rahim Yar Khan, from July 2017 to January 2018.

Sample size was calculated by taking confidence level of $95 \%$, power of $80 \%$, and expected proportion in group $\mathrm{A}$ 
$100 \%, 12$ and in group B $71 \% ; 13$ and 20 in each group was calculated and finally increased to 25 in each group.

The cases of $C L$ of age range of 12 years or more were included. Detailed sociodemographic data and clinical data like duration, site, size and number of lesions and presence of secondary infection were also recorded. The diagnosis of CL was made on the basis of history to endemic area and clinical features of erythematous papules, nodule and non healing ulcer and on detection of amastigotes on Giemsa staining on smear taken from the involved site. The cases with allergic to any of these agents, pregnant ladies, children below 12 years, cases with end-stage hepatic or renal failure and those who were taking any treatment for this in the last one month were excluded from this study.

The cases were recruited by simple random sampling divided into two groups, i.e. A and $B$ by random sampling method. Group A was treated with chloroquine in a dose of $250 \mathrm{mg}$ twice daily per oral ( $10 \mathrm{mg} / \mathrm{kg} / \mathrm{day}$ ) and group B was treated with doxycycline in a dose of $200 \mathrm{mg}$ daily per orally $(3.3 \mathrm{mg} / \mathrm{kg} / \mathrm{day})$. Patients were followed up fortnightly and examined for number, induration and healing of lesion and inquired about any systemic side effects. Ophthalmic evaluation was done before and after the treatment. Efficacy was labelled as 'yes' where there was complete re-epithelisation or healing with or without scarring of the lesions with no more induration. Patients were called for follow up after three months. Ethical approval was sought from Institutional Review Board and informed verbal consent was taken from every patient before inclusion in the study.

The data was entered and analysed with the help of SPSS version 23. Descriptive statistics were calculated as mean \pm 5 standard deviation by age and duration of lesions. Effect modifiers were controlled through stratification and post-stratification Chi-square test and independent sample t-test was applied for comparing age and duration of lesions taking $p$-value less than 0.05 as significant, Chi-square test was applied to compare efficacy of both drugs.

\section{RESULTS}

In the present study, there were a total of 50 cases, 25 in each group. As far as descriptive statistic are concerned, mean age in group $A$ and $B$ was $30.56 \pm 7.14$ and $27.96 \pm 6.97$, respectively with $p=0.199$. There was no significant difference in terms of duration of lesion1.28 \pm 0.46 versus $1.24 \pm 0.44$ days with $p=0.753$. All cases were from rural population and endemic areas. There was also no difference in terms of site of lesion; whereas the hand and arms were the most common site in both groups with $p=0.34$ (Table I).

The efficacy in group A was $100 \%$, while in group B it was $23(92 \%)$ of cases (Table I) with $p=0.14$. Table I reveals
Table I: Site of lesions, efficacy and time taken for efficacy in both groups $\mathrm{n}=25$ in each

\begin{tabular}{|c|c|c|c|}
\hline \multirow[t]{2}{*}{ Variable } & \multicolumn{2}{|c|}{ Treatment groups } & \multirow[t]{2}{*}{$p$-value } \\
\hline & Group A & Group B & \\
\hline \multicolumn{4}{|c|}{ Site of lesions in both groups } \\
\hline Hands and arms & $14(56 \%)$ & $17(68 \%)$ & 0.34 \\
\hline Feet and legs & $7(28 \%)$ & $7(28 \%)$ & \\
\hline Face & $1(04 \%)$ & $1(4 \%)$ & \\
\hline Body & $3(12 \%)$ & $0(00 \%)$ & \\
\hline Total & $25(100 \%)$ & $25(100 \%)$ & \\
\hline \multicolumn{4}{|c|}{ Efficacy of drugs in both groups } \\
\hline Yes & $25(100 \%)$ & $23(92 \%)$ & 0.14 \\
\hline No & $00(00 \%)$ & $2(8 \%)$ & \\
\hline Total & $25(100 \%)$ & $25(100 \%)$ & \\
\hline \multicolumn{4}{|c|}{ Time taken for efficacy in both groups } \\
\hline 2 week & $1(4 \%)$ & $0(0 \%)$ & 0.48 \\
\hline 4 week & $2(8 \%)$ & $1(4 \%)$ & \\
\hline 6 week & $2(8 \%)$ & $2(8 \%)$ & \\
\hline 8 week & $7(28 \%)$ & $5(20 \%)$ & \\
\hline 10 week & $12(48 \%)$ & $11(44 \%)$ & \\
\hline 12 week & $1(4 \%)$ & $4(16 \%)$ & \\
\hline No effficacy & $0(0 \%)$ & $2(8 \%)$ & \\
\hline Total & $25(100 \%)$ & $25(100 \%)$ & \\
\hline
\end{tabular}

duration of treatment of disease was less in chloroquine group. There was no side effect noted in both the groups.

\section{DISCUSSION}

$\mathrm{CL}$ is prevalent in almost all countries globally and as part of that, it is also found in few endemic areas of Pakistan. 14,15 Treatment is required due to its complications like disfiguring scar and limited mobility of affected joint and others. ${ }^{16}$ This study assessed the efficacy of oral chloroquin and oral tetracycline in treatment of $\mathrm{CL}$.

It is treated by various ways; and among them, antimonials are the most commonly employed modality; but there are few limitations while using it, as it is not easily available, and a significant number of cases suffer from side effects; and the emerging resistance is another point of concern in such cases.2,3 Therefore, search for both safer and effective options for treatment of $\mathrm{CL}$ continues.

In the present study, the efficacy of the oral chloroquine was $100 \%$ as compared to tetracycline, where it was seen in $23(92 \%)$ of the cases with $p$ value of 0.14 . It shows that efficacy of both of the two regions is not statistically significantly different, hence either of these can be used in the treatment of CL.

Chloroquine has been found to be effective both oral and intra-lesional in the treatment of CL by Yasmin et al., intra-lesional chloroquine was compared with intralesional meglumine antimoniate, and this treatment was continued for eight weeks and it was seen that the efficacy of chloroquine was $100 \% .{ }^{9}$ In another study, where oral chloroquine was used in comparison with 
intra-lesional pentavalent antimony, the efficacy was again found to be $100 \%$ with chloroquine, while $93 \%$ in the anti-monial group. 10 According to a study done by Hanif et al., they compared intra-lesional and oral chloroquine and it was seen that it was efficacious in $100 \%$ of the cases in both the groups. 12 Furthermore, they also revealed that the economic cost was minimal with this and also majority of the cases responded after eight weeks of treatment, which is also observed in our study.

The efficacy of doxycycline was also good in the previous studies. It has not been used previously except once. According to a study done by Mamoudi et al., the efficacy was seen in $10(71.42 \%)$ out of 14 cases reported with leishmaniasis. ${ }^{13}$

No significant side effects were seen in previous studies as well as in the present study. Therefore, it can be used as safe and easily available, cost-effective alternative of previous treatment options for cutaneous leishmanisis.

Above mentioned drugs have proven efficacy in the treatment of $\mathrm{CL}$; but there was no direct one-to-one comparison between these two drugs. The present study compares these drugs to find out better option for the treatment of CL. Additionally, number of lesions was not counted in patients.

This study did not include females and children of less than 12 years. There was no placebo group taken in this study, therefore, the possibility of spontaneous cure was not assessed.

\section{CONCLUSION}

Oral tetracycline is as efficacious as oral chloroquine in the treatment of cutaneous leishmaniasis.

\section{REFERENCES}

1. Khan SJ, Muneeb S. Cutaneous leishmaniasis in Pakistan. Dermatol Online J 2005; 11:4.

2. Ali A, Rehman T, Qureshi NA, Rahman H. New endemic focus of cutaneous leishmaniasis in Pakistan and future epidemics threats. Asian Pacific J Trop Dis 2016; 6:155-9.
3. Saadabadi F, Mohajery M, Poostchi E, Shamsian SA. Identification of leishmania species causing cutaneous leishmaniasis using random amplified polymorphic DNA (RAPD-PCR) in Kharve, Iran. Rep Biochem Mol Biol 2013; 1:69-73

4. Dedet JP, Pratlong F.. Leishmaniasis. In: Manson P, Cook GC, Zumla Al, Eds. Manson's tropical diseases. ed. 21 $1^{\text {st }}$, London: WB Saunders; 2003: p.1339-64.

5. Sami Ullah, Abdul Hamid Jan, Shad Mohammad Wazir, Nawab Ali. Prevalence of cutaneous leishmaniasis in Lower Dir district, (N.W.F.P) Pakistan. JPAD 2009; 19:212-5.

6. Bhutto AM, Soomro RA, Nonaka S, Hashiguchi Y. Detection of new endemic areas of cutaneous leishmaniasis in Pakistan: A 6-year study. Int J Dermatol 2003; 42:543-8.

7. Vega-Lopez F, Hay RJ. Parasitic worms and protozoa. Rook's textbook of dermatology. $8^{\text {th }}$ Edn. ed: Wiley Blackwell; 2010:37-43.

8. WHO model prescribing information. Drugs used in parasitic diseases: Second edition. 1995; 152.

9. Rocha VP, Nonato FR, Guimarães ET, Rodrigues de Freitas LA, Soares MB. Activity of antimalarial drugs in vitro and in a murine model of cutaneous leishmaniasis. J Med Microbial 2013; 62:1001-10.

10. de Vries HJ, Reedijk SH, Schallig HD. Cutaneous leishmaniasis: Recent developments in diagnosis and management. $A m \mathrm{~J}$ Clin Dermatol 2015; 16:99-109.

11. Monge-Maillo B, López-Vélez R. Therapeutic options for old world cutaneous leishmaniasis and new world cutaneous and mucocutaneous leishmaniasis. Drugs 2013; 73:1889-920.

12. Yasmin IK, Ahmed SA. Response to treatment of cutaneous leishmaniasis with intralesional chloroquine versus intralesional meglumine antimoniate. JPAD 2011; 21:270-5.

13. Khan RY, Yasmin R, Siddiqui I. Chloroquine in cutaneous leishmaniasis. JPAD 2007; 17:95-100.

14. Khairulin Fla, Ereshov ME, Khuseiinova KhKh, Rozyreva AA, Sukhanova TA. Treatment of cutaneous leishmaniasis with methacycline and doxycycline (vibramycin). Vestn Dermatol Venerol 1989; 3:62-6.

15. Hanif MM, Akram K, Mustafa G. Intralesional versus oral chloroquine in cutaneous leishmaniasis; Comparison of outcome, duration of treatment and total dose of drug. J COII Physians Surg Pak 2016; 26:260-2.

16. Masmoudi A, Dammak A, Chaaben H, Maalej N, Akrout F, Turki H. Doxycycline for the treatment of cutaneous leishmaniasis. Dermatol Online J 2008; 14:1-3. 